\title{
$5000 \mathrm{ppm}$ toothpaste more effective than $1100 \mathrm{ppm}$ in reversing root caries
}

\section{In people who have primary root caries, is $5000 \mathrm{ppm}$ fluoride dentifrice more effective than $1100 \mathrm{ppm}$ dentifrice in reversal of lesions?}

\section{Baysan A, Lynch E, Ellwood R, Davies R, Petersson L, Borsboom $\mathrm{P}$. Reversal of primary root caries using dentifrices containing 5,000 and 1,100 ppm fluoride. Caries Res 2001; 35:41-46}

Design Six-month double-blind randomised trial of 186 adults who each had to least one PRCL.

Intervention Verbal and written instructions were given to participants to brush at least once a day with the allocated dentifrice. Toothbrushes and dentifrices were supplied.

Outcome measure New lesions were assessed by a single examiner using fixed clinical criteria and an electric caries monitor (ECM).

Results After 6 months, significantly more lesions in the $5000 \mathrm{ppm}$ group had reversed (see Table 1). Non-cavitated lesions were more likely to harden. ECM scores in the $5000 \mathrm{ppm}$ group tended to increase during the study.

Conclusions The dentifrice containing $5000 \mathrm{ppm}$ fluoride was found to be significantly better at remineralising PRCL than the one containing 1100 ppm fluoride.

Acknowledgement This study was supported by a grant from Colgate Palmolive.

Table 1. Effect of 1100 and $5000 \mathrm{ppm}$ fluoride on primary root carries lesions (PRCL).

\begin{tabular}{lcc}
\hline & \multicolumn{2}{c}{ Fluoride level in dentifrice } \\
\cline { 2 - 3 } & $5000 \mathrm{ppm}$ & $1100 \mathrm{ppm}$ \\
\hline Subjects at baseline $(\mathrm{n})$ & 107 & 94 \\
Subjects with $>1$ PRCL reversed at & 58 & 24 \\
6 months & & \\
NNT $(95 \% \mathrm{Cl})$ & $3(2-6)$ & \\
\hline
\end{tabular}

NNT, numbers-needed-to-treat; $\mathrm{Cl}$, confidence interval.

\section{Commentary}

With the trend to retention of natural teeth, ${ }^{1}$ root caries is likely to become on increasing component of the burden of illness among older adults in developed countries. The literature dealing with the prevention, reversal and restoration of root caries is not extensive and clinicians lack strong guidance for the appropriate management of the condition. ${ }^{2}$ Thus, this study addresses an important clinical problem.

The investigators set out to compare the ability of two sodium fluoride dentifrices to remineralise primary root caries. This report of 6-month findings follows an earlier publication of the results of the dentifrice's efficacy in arresting lesions. ${ }^{3}$

Address for correspondence: Aylin Baysan, St Bartholomew's and the London School of Medicine and Dentistry, Department of Adult Dental Health, Turner Street, Whitechapel, London E1 2AD, UK. E-mail: a.baysan@mds.qmw.ac.uk
The investigators obtained ethical approval for the study and they used a strong design, the double-blind randomised trial. Caries was assessed by means of three clinical criteria (hardness, area, colour) plus the ECM. The investigators report very high measures of reproducibility of the clinical criteria tested on 15 teeth in 12 subjects but do not provide information on the length of time between the two examinations. The intraclass coefficient between the first and second ECM measures was 0.75 (95\% confidence interval, 0.41-0.91). Although instructions for both groups were to brush once per day and use no other fluorides, there is no record of compliance with the test regimens, nor whether compliance was equal among the groups. None of the measures of root caries has been validated against a gold standard such as histology, but they are widely accepted. ${ }^{2}$ The investigators' findings favoured the $5000 \mathrm{ppm}$ dentifrice and were consistent no matter what clinical criteria was used, lending credibility and suggesting that their findings are clinically valid. Guidelines developed in 1988 for clinical trials of anticaries devices state that, "caries clinical trials within the Unites States should run for at least 2 years". ${ }^{4}$ The guidelines state, further, that efficacy is confirmed only after two clinical trails, presumably from different teams of investigators. Whether US criteria to guide trials of agents to prevent enamel caries should apply to remineralisation studies of root caries in the rest of the world 14 years later is an open question. These findings are consistent with other studies that have shown that high concentrations of fluoride in other forms can remineralise root caries lesions. ${ }^{2}$ Nonetheless, 6 -month results from one study must be accepted with caution.

\section{Practice points}

- This is an increasingly important clinical issue.

- Consistent with other studies, high concentrations of fluoride here appear to remineralise root caries lesions.

- This is a single small study so results must be accepted with caution.

\section{James Leake}

Department of Biological and Diagnostic Sciences, Faculty of Dentistry, Toronto University, Toronto, Canada

1. Kelly M, Steele J, Nuttal N, et al. Adult Dental Health Survey: Oral Health in the United Kingdom 1998, London: Government Statistical Service. 2000.

2. Leake JL. Clinical decision making for caries management in root surfaces. J Dent Edu 2001; 65:1147-1153.

3. Lynch E, Baysan A, Ellwood R, Davies R, Petersson L, Borsboom P. Effectiveness of two fluoride dentifrices to arrest root carious lesions. Am J Dent 2000; 13:218-220.

4. American Dental Association. Council on Dental Therapeutics, Report of the workshop aimed at defining guidelines for caries clinical trials: superiority and equivalency claims for anticaries dentifrices. JADA 1988; 117:663-665. 